ARQGA/1199

\title{
p53 NA PRÁTICA CLÍNICA: sim ou não?
}

DESCRITORES - Genes p53. Polimorfismo (genética). Prognóstico. Neoplasias colorretais.

Nas últimas décadas ocorreu uma verdadeira revolução no conhecimento do câncer humano. A Biologia Molecular propiciou o entendimento de determinados aspectos da carcinogênese antes não elucidados, assim como se reconheceu a natureza gênica dessa doença.

O câncer colorretal origina-se de células normais que expostas a várias agressões genotóxicas, resultam no acúmulo de mutações ou fenômenos epigênicos em poucos, porém importantes, genes que favorecem à célula, a proliferação clonal e a imortalização. Esta cascata de mutações foi extensivamente estudada e correlaciona-se precisamente com a progressão da neoplasia, sendo o p53 um dos genes alterados mais prevalentes nesta neoplasia ${ }^{(17)}$.

O gene $\mathrm{p} 53$ foi identificado há mais de duas décadas; desde então, o conhecimento sobre sua função, os mecanismos envolvidos em sua regulação, os efeitos de sua inativação, a participação e ativação de outros genes, a associação com fenótipo e a utilização na terapia gênica não cessam e, portanto, a literatura afim é vasta ${ }^{(3)}$; até janeiro de 2006 pode-se verificar a citação de 38.402 artigos científicos no PubMed usando-se o critério "p53 or TP53"; 2492 sobre "p53 or TP53" e câncer colorretal e 271 somente sobre câncer retal e "p53 or TP53".

O gene supressor de tumor, p53, está localizado no cromossomo $17 \mathrm{p}$, codifica uma proteína nuclear de $53 \mathrm{kD}$ e é o gene mais comumente envolvido na carcinogênese humana $^{(1,4)}$. Os exons 5 a 8 são os que sofrem maior número de mutações, já que compreendem regiões altamente conservadas durante a evolução dos vertebrados, sugerindo alto grau de importância funcional. A proteína p53 normal tem efeito inibitório na proliferação e na transformação celular, mantendo as células em repouso na fase G1 do ciclo celular ${ }^{(1)}$.

As mutações do p53 aparecem em etapas específicas durante a transformação maligna ${ }^{(4,17)}$. Mutações do gene p53 geralmente coincidem com o aparecimento de carcinoma in situ, como por exemplo: de cólon, trato digestório alto, mama e bexiga. Em alguns casos, a alteração do p53 coincide com a emergência de tumores biologicamente agressivos e a perda da diferenciação celular, como tumor anaplásico de Wilms, tumor de tireóide, glioma maligno ou anaplásico, melanoma metastático e invasivo, e câncer de próstata ${ }^{(4,17)}$.

Nos tumores colorretais, perda de alelo e mutação no gene p 53 ocorre em mais de $60 \%$ dos casos. Além disto, a proteína é detectada em $30 \%$ dos adenomas e em $40 \%$ a $60 \%$ dos adenomas com displasia de alto $\operatorname{grau}^{(9,15)}$.

Neste número dos ARQUIVOS de GASTROENTEROLOGIA publicam-se duas contribuições relevantes para o entendimento da participação do $\mathrm{p} 53$ no contexto clínico de pacientes com câncer colorretal. No primeiro, LIMA et al. ${ }^{(7)}$, relatam a experiência da Universidade Federal de São Paulo quanto à avaliação de polimorfismo do códon 72 do gene p53 em 100 pacientes com câncer colorretal e 100 indivíduos sem câncer, pareados quanto ao sexo e idade, e alguns fatores de risco, como por exemplo o tabagismo e o etilismo. Os autores não conseguiram demonstrar associação com risco aumentado de câncer e o polimorfismo estudado, entretanto os doentes em estádio mais avançado apresentaram genótipo homozigoto em maior prevalência. No segundo estudo, JURACH et al.( ${ }^{(6)}$, da Universidade Federal do Rio Grande do Sul, reportam dados de 83 pacientes com câncer do reto tratados em Porto Alegre e submetidos a análise imunoistoquímica do p53. A imunoexpressão do p53 associou-se com o estádio, histologia e recurrência. Ademais, a imunoexpressão do p53 revelou ser fator prognóstico independente nesse grupo de pacientes.

Relatos recentes sugerem que polimorfismo do gene $\mathrm{p} 53$, que resulta na substituição de prolina por arginina na posição do códon 72 desse gene, aumenta o risco para transformação maligna do adenoma para o adenocarcinoma $^{(8)}$, assim como permite o aparecimento mais precoce de tumores em indivíduos com câncer colorretal hereditário não-polipóide ${ }^{(5)}$. Em indivíduos com câncer colorretal esporádico no Brasil o polimorfismo mencionado não se associou a risco aumentado de câncer(7), como evidenciaram outros autores ${ }^{(16)}$.

Como demonstrado na pesquisa de JURACH et al. ${ }^{(6)}$, a imunoexpressão de p53 pode ter valor prognóstico em pacientes com câncer retal, pois maior índice de detecção da proteína tem sido demonstrado em tumores com maior envolvimento linfonodal, como também a sobrevivência de 5 anos é menor nos casos com tumor positivo para 553 , quando comparada aos casos negativos ${ }^{(10)}$. A detecção de mutação do $\mathrm{p} 53$ e a perda de alelo representam marcadores de prognóstico desfavorável ${ }^{(10,12,14)}$, todavia a utilidade da imunoistoquímica ainda é duvidosa e apresenta resultados conflitantes ${ }^{(2,9,11,13)}$. Apesar disso, geralmente ocorre forte associação entre imunoexpressão do p53 e análise gênica nos tumores retais, havendo falhas ao redor de $10 \%$ a $20 \%$ dos $\operatorname{casos}^{(18)}$. 
A interpretação da demonstração imunoistoquímica da proteína p53 é baseada na premissa de que o p53 selvagem tem meia-vida curta, não sendo detectável ${ }^{(1)}$. As mutações do p53 tornam a proteína mais estável e, portanto, detectável. Contudo, coloração positiva para p53 não implica, necessariamente, em mutação, desde que a degradação reduzida e o ambiente celular alterado podem, similarmente, tornar a proteína p53 selvagem detectável ${ }^{(3,18)}$. Da mesma maneira, a ausência de coloração pode ocorrer em casos de deleção do gene, falência de transcrição ou de mutação não estável; todas as referidas situações podem estar associadas com perda de função do p53 $3^{(3,18)}$.

Esses resultados conflitantes ora apresentados, sugerem que estudos prospectivos com maior número de pacientes, seguimento longo (maior do que 5 anos), tratamento uniforme e metodologia de detecção das alterações bem padronizada talvez possam esclarecer definitivamente a importância desse gene na evolução dos pacientes.

Vários marcadores moleculares promissores têm sido identificados para os tumores colorretais; entretanto, até o momento permanecem no plano experimental, principalmente em virtude da variabilidade nos métodos de detecção empregados. A maioria dos estudos de marcadores moleculares apresenta pequeno número de casos, com campo de ação limitado e às vezes com informações contraditórias. Adicionalmente, a maioria das investigações não discrimina entre tumores localizados no reto daqueles localizados no restante do cólon. Por exemplo, o p53 tem sido avaliado através de perda da heterozigose, imunoistoquímica e detecção de mutações pelo seqüenciamento direto. Mesmo através de um único método, os resultados podem variar consideravelmente, acarretando numa interpretação extremamente difícil dos dados.

Com o enorme volume de informações sobre Biologia Molecular do câncer, espera-se que se possa utilizá-las para melhor prevenção, diagnóstico precoce, tratamento e seguimento dos doentes. É iminente vermos os aspectos moleculares e gênicos serem incorporados na prática clínica diária. Devemos, neste momento, desenhar ensaios clínicos com algumas variáveis moleculares de prognóstico, com número adequado de pacientes, em tempo razoável, sem subestimar dados clínicos de relevância usando padrões definidos de eficácia.

Parece razoável buscar a estratégia de selecionar pacientes em melhores e piores respondedores a algum tipo de tratamento padronizado, e então avaliar um painel de marcadores moleculares com presumível valor prognóstico ou valor preditivo. A verificação de que a imunoexpressão do p53 se associa a pior prognóstico seja quanto ao índice de recidiva de doença, ou quanto ao índice de menor sobrevivência, abre perspectivas para linha de pesquisa que poderá proporcionar progresso científico. A inclusão desses marcadores no conjunto de procedimentos em amostras de biopsia, em conjunto com o cuidadoso estádio anatomopatológico nos espécimes cirúrgicos, pode permitir a confecção de algoritmos, que poderão auxiliar no planejamento terapêutico e nas medidas de vigilância evolutiva de pacientes com adenocarcinoma colorretal.

Por enquanto, esses exames ainda não podem ser recomendados para uso clínico para escolha individualizada de tratamento, apesar de prover melhor informação para o entendimento da patogênese e ser usado em protocolos terapêuticos. A realização e publicação de estudos cuidadosamente planejados, randômicos e com número suficiente de pacientes poderão confirmar o potencial uso do $\mathrm{p} 53$, assim como de outros marcadores em futuro breve.

\section{Ulysses RIBEIRO Jr.* Adriana Vaz SAFATLE-RIBEIRO*}

Ribeiro Jr U, Safatle-Ribeiro AV. p53 in clinical contexts: yes or not? Arq Gastroenterol 2006;43(1):6-7.

HEADINGS - Genes, p53. Polymorphism (genetics). Prognosis. Colorectal neoplasms.

\section{REFERÊNCIAS BIBLIOGRÁFICAS}

1. Finlay CA, Hinds PW, Levine AJ. The $\mathrm{p} 53$ protooncogene can act as a suppressor of transformation. Cell. 1989;57:1083-93.

2. Forones NM, Oshima C, Nanogaki S, Tanaka M, Barbosa V. Determinação da atividade proliferativa pelo Ki-67 e p53 em doentes com câncer colorretal. Arq Gastroenterol. 1999;36:122-6.

3. Hall PA, McCluggage WG. Assessing p53 in clinical contexts: unlearned lessons and new perspectives. J Pathol. 2006;208:1-6.

4. Hollstein MC, Sidranski D, Vogelstein B, Harris CC. p53 mutations in human cancers. Science. 1991;253:49-53.

5. Jones JS, Chi X, Gu X, Lynch PM, Amos CI, Frazer ML. p53 polymorphism and age of onset of hereditary nonpolyposis colorectal cancer in a Caucasian population. Cin Cancer Res. 2004;10:5845-9.

6. Jurach MT, Meurer L, Moreira LF. Expression of the $\mathrm{p} 53$ protein and clinical and pathologic correlation in adenocarcinoma of the rectum. Arq Gastroenterol. 2006;43:14-9.

7. Lima JM, Serafim PVP, Silva IDCG, Forones NM. Estudo do polimorfismo genético no gene p53 (códon 72) em câncer colorretal. Arq Gastroenterol. 2006;43:8-13.

8. Lung FW, Lee TM, Shu BC, Chang FH. p53 codon 72 polymorphism and susceptibility malignancy of colorectal cancer in Taiwan. J Cancer Res Clin Oncol. 2004;130:728-32.

9. Rawet V. Carcinoma colorretal: estadiamento e parâmetros prognósticos [tese]. São Paulo: Faculdade de Medicina da Universidade de São Paulo; 1998.

10. Rebischung C, Gerard JP, Gayet J, Thomas G, Hamelin R, Laurent-Puig P. Prognostic value of p53 mutations in rectal carcinoma. Int J Cancer. 2002;100:131-5.
11. Remvikos Y, Tominaga O, Hammel P, Laurent-Puig P, Salmon RJ, Dutrillaux B, Thomas G. Increased $\mathrm{p} 53$ protein content of colorectal tumours correlates with poor survival Br J Cancer. 1992;66:758-64.

12. Ribeiro Jr U, Finkelstein SD, Safatle-Ribeiro AV, Landreneau RJ, Clarke MR, Bakker A, Swalsky PA, Gooding WE, Posner MC. p53 sequence analysis predicts treatment response and outcome of patients with esophageal carcinoma. Cancer. 1998;83:7-18.

13. Ribeiro Jr U, Alves VA, Souza PMSB, Safatle-Ribeiro AV, Rawet V, Nonogaki S, GamaRodrigues JJ, Habr-Gama A. Correlação das proteínas p53 e Ki67 com o prognóstico de pacientes com adenocarcinoma de reto distal. Rev Bras Coloproctol. 2000;20:248-56.

14. Russo A, Bazan V, Iacopetta B, Kerr D, Soussi T, Gebbia N. The TP53 Colorecta Cancer International Collaborative Study on the prognostic and predictive significance of p53 mutation: influence of tumor site, type of mutation, and adjuvant treatment. J Clin Oncol. 2005;23:7518-28.

15. Sartor MC. Comparação entre a apoptose celular, a expressão do antígeno cárcinoembrionário e do p53 em pólipos colônicos benignos e câncer [tese]. São Paulo: Faculdade de Medicina da Universidade de São Paulo; 2000.

16. Sotamaa K, Liyanarachchi S, Mecklin JP, Jarvinen H, Aaltonen LA, Peltomaki P, de La Chapelle A. p53 codon 72 and MDM2 SNP309 polymorphisms and age of colorectal cancer onset in Lynch syndrome. Clin Cancer Res 2005;11:6840-4.

17. Vogelstein B, Fearon ER, Hamilton SR, Kern SE, Preisinger AC, Leppert M, Nakamura Y, White R, Smits AMM, Bos JL. Genetic alterations during colorectal-tumor development. N Engl J Med. 1988;319:525-32.

18. Wynford-Thomas D. p53 in tumor pathology: can we trust immunocytochemistry? J Pathol. 1992;166:329-30.

* Departamento de Gastroenterologia da Faculdade de Medicina da Universidade de São Paulo. 